\title{
Inflammatory markers in chronic obstructive pulmonary disease patients with different $\alpha 1$ antitrypsin genotypes
}

\author{
Danielius Serapinas ${ }^{1,2}$, Brigita Sitkauskiene ${ }^{1}$, Raimundas Sakalauskas ${ }^{1}$
}

1Department of Pulmonology and Immunology, Medical Academy, Lithuanian University of Health Sciences, Kaunas, Lithuania

${ }^{2}$ Mykolas Romeris University, Vilnius, Lithuania

Submitted: 20 September 2010

Accepted: 5 December 2010

Arch Med Sci 2012; 8, 6: 1053-1058

DOI: 10.5114/aoms.2012.32414

Copyright @ 2012 Termedia \& Banach

\section{Abstract}

Introduction: Chronic obstructive pulmonary disease (COPD) has been recently defined as a systemic pulmonary inflammatory disease, and congenital $\alpha 1$ antitrypsin deficiency is one of the well-established genetic risk factors for chronic obstructive pulmonary disease. The aim of our study was to evaluate the possible associations of $\alpha 1$ antitrypsin with inflammatory markers - CRP, sCD14, TNF- $\alpha$, STNFR-1, and STNFR-2 - in patients with COPD with different $\alpha 1$ antitrypsin genotypes.

Material and methods: Serum biomarkers from patients $(n=355)$ with COPD, defined according to the GOLD criteria, were analyzed using commercial ELISA kits; $\alpha 1$ antitrypsin concentrations were determined by nephelometry, and $\alpha 1$ antitrypsin phenotyping was carried out by means of isoelectric focusing. Results: No significant differences in CRP, TNF- $\alpha$, sTNFR-1, sTNFR-2, and SCD14 levels were found comparing COPD patients with different genotypes. In patients without $\alpha 1$ antitrypsin deficiency $\left(P I^{*} M M\right)$, a significant negative correlation between lung function $\left(\mathrm{FEV}_{1}\right)$ and serum $\alpha 1$ antitrypsin $(r=-0.522, p=0.03)$ and CRP concentration ( $r=-0.590, p=0.011)$ was detected. The level of $\alpha 1$ antitrypsin positively correlated with: a) CRP concentration ( $r=0.671, p=0.005)$, b) $\operatorname{SCD14}(r=0.510, p=0.008)$ and c) STNFR-1 $(r=0.567, p=0.007)$.

Conclusions: In patients without $\alpha 1$ antitrypsin deficiency, the positive association of $\alpha 1$ antitrypsin concentration with CRP, SCD14, and STNFR-1 and the negative association with $\mathrm{FEV}_{1}$ show the importance of $\alpha 1$ antitrypsin as a marker of systemic inflammation.

Key words: chronic obstructive pulmonary disease, $\alpha 1$ antitrypsin, inflammatory markers.

\section{Introduction}

Chronic obstructive pulmonary disease (COPD) is a prevalent and costly disease characterized by progressive airflow limitation, related to an abnormal inflammatory response of the lung to long-term tobacco smoke or inhalation of toxic gases [1]. Lung inflammation is further amplified by oxidative stress and proteolytic damage by proteinases [2]. There is increasing evidence of systemic inflammation in patients with COPD [3-8]. Thus, changes of inflammatory mediators can be evaluated not only in the airways and other pulmonary compartments but also in blood [3].
Corresponding author:

Danielius Serapinas PhD

Department of Pulmonology and Immunology

Medical Academy

Lithuanian University

of Health Sciences

Eiveniu 2

Kaunas LT 50028, Lithuania

Phone: +37037326771

Fax: +37037326953

E-mail:

dserapinas@gmail.com 
The prevalence of COPD is appreciably higher in current or former heavy smokers aged more than 40 years. However, there is consistent evidence that only $15-30 \%$ of smokers develop COPD [1] and some nonsmokers may also develop chronic airflow obstruction, suggesting that the risk of COPD results from a gene-environment interaction. $\alpha 1$ Antitrypsin (AAT) deficiency is the best-described genetic risk factor for COPD. The primary function of AAT is to inhibit neutrophil elastase. In severe deficiency, anti-elastase protection in the lung interstitium and alveolar space is markedly decreased to about $15-20 \%$ of normal levels, similar to the decrease in plasma levels [9-11]. Most of the pathologies related to AAT deficiency are linked to the $\mathrm{PI}^{\star} \mathrm{Z}$ allele, and in clinical practice, $96 \%$ of Patients with AAT deficiency have a $\mathrm{PI}^{\star} \mathrm{ZZ}$ genotype. The remaining $4 \%$ have $\mathrm{PI}^{\star} \mathrm{SZ}, \mathrm{PI}^{\star} \mathrm{MZ}$, and other rare deficiency genotypes [9].

An important mediator of inflammation in COPD patients is tumor necrosis factors $\alpha$ (TNF- $\alpha$ ), produced primarily by activated macrophages [8]. Tumor necrosis factor $\alpha$ exerts its diverse biological effects by binding to two specific cell membrane receptors (mTNFR-1 and mTNFR-2), expressed on a variety of cells. Both receptors can be shed from the cell surface to form soluble TNF- $\alpha$ receptors, sTNFR-1 and STNFR-2, which can compete with mTNFRs as ligands to TNF and thereby inhibit the effects of TNF- $\alpha$ [8].

Another mechanism leading to a proteaseantiprotease imbalance in the lungs during antitrypsin deficiency ( $\mathrm{PI}^{\star} \mathrm{ZZ}$ phenotype) is that $\mathrm{Z}$ antitrypsin polymerizes abnormally in the lungs and acts as a neutrophil chemo-attractant, leading to the recruitment of neutrophils to the lungs [14]. It has been recently shown that AAT regulates many physiological and pathological processes, which may significantly influence the disease process, including cell-mediated immunity, apoptosis, tumor cell growth, and many others [15]. $\alpha 1$ Antitrypsin has even been shown to regulate expression of CD14, a receptor for lipopolysaccharides (LPS), in human monocytes in vitro [16]. However, the potential role of systemic inflammation in the pathogenesis of COPD with different AAT genotypes has not been well established yet.

The aim of our study was to evaluate the possible associations between AAT and inflammatory markers - C-reactive protein (CRP), soluble CD14 (sCD14), TNF- $\alpha$, sTNFR-1, and sTNFR-2 - in patients with COPD with different AAT genotypes.

\section{Material and methods}

\section{Subjects}

The patients for this study were recruited from the regional AAT deficiency and COPD registry of the Department of Pulmonology and Immunol- ogy, Medical Academy, Lithuanian University of Health Sciences. From the registry, a total of 538 COPD patients without AAT deficiency (PI* MM) were randomly selected, and all 53 patients with AAT deficiency $\left(\mathrm{PI}^{\star} \mathrm{MZ}, \mathrm{PI}{ }^{\star} \mathrm{SZ}\right.$, and $\mathrm{PI}{ }^{\star} \mathrm{ZZ}$ genotypes) were selected. From 591 patients invited by post, 392 patients (66\%) arrived and agreed to participate in the study. Out of 392 patients, 355 COPD patients (320 and 35 without and with AAT deficiency, respectively) met the following criteria: no use of oral corticosteroids or leukotrienes for at least 6 weeks prior to the study, none of the subjects showed signs of acute respiratory infection at least a month before the investigation, patients were free of systemic steroids for at least 1 month before the study. The patients also met the GOLD [1] spirometric criteria for COPD (ratio of postbronchodilator forced expiratory volume in $1 \mathrm{~s}\left(\mathrm{FEV}_{1}\right)$ to forced vital capacity (FVC) less than $70 \%$ of predicted). Smoking history was calculated in packyears as the product of tobacco use (in years) and the average number of cigarettes smoked per day/20 (years $\times$ cigarettes per day/20). The study design was approved by the Regional Ethics Committee, and all studied subjects gave their informed consent.

\section{Sample collection and evaluation}

Blood samples were drawn in serum tubes, clotted at room temperature $\left(22^{\circ} \mathrm{C}\right)$ for $30-60 \mathrm{~min}$, and centrifuged for $15 \mathrm{~min}$ at $4000 \mathrm{rpm}$. Serum samples were immediately frozen at $-70^{\circ} \mathrm{C}$ for further analysis. Serum concentrations of AAT were determined by nephelometry (Dade Behring Marburg $\mathrm{GmbH}$, Germany) according to the manufacturer's instructions. sCD14, TNF- $\alpha$, sTNFR-1 and STNFR-2 levels were determined using Duosit ELISA sets (R\&D Systems, MN, USA; detection levels $125 \mathrm{pg} / \mathrm{ml}$, $15.6 \mathrm{pg} / \mathrm{ml}$ and $25 \mathrm{pg} / \mathrm{ml}$, respectively). Analysis of CRP in serum was performed using standard assays (Dade Behring, USA, minimum detection level less than $0.15 \mathrm{mg} / \mathrm{l}$ ). $\alpha 1$ Antitrypsin phenotyping was carried out by isoelectric focusing (LKB Multiphor II and LKB Macrodrive 5 Constant Power Supply, Amarcham Pharmacia Biotech, Piscataway, NJ, USA) as described previously [17].

\section{Statistical analysis}

Statistical analysis was performed using the SPSS 14.0 program. Descriptive statistics were used to tabulate the primary cohort database. Quantitative variables were expressed as means with standard deviations (SD). The differences among means were analyzed for their statistical significance with the one-way ANOVA. The interrelationships among variables were determined using Spearman correlation. A $p$ value of less than 0.05 was considered significant. 


\section{Results}

Demographic data of the 355 studied COPD patients are shown in Table I. The distribution of patients by genotypes was as follows: $320(90.1 \%)$ patients with $\mathrm{Pl}^{*} \mathrm{MM}$ genotype, $25(7 \%)$ with $\mathrm{Pl}^{*} \mathrm{MZ}$ genotype, 7 (2\%) with $\mathrm{PI}{ }^{\star} \mathrm{ZZ}$ genotype, and $3(0.9 \%)$ with $\mathrm{Pl}^{\star} \mathrm{SZ}$ genotype.

The values of serum biomarkers - AAT, CRP, CD14, TNF- $\alpha$, sTNFR-1 and sTNFR-2 - in the groups with different AAT genotypes are presented in Table II. Except for expected lower AAT serum concentrations in COPD patients with AAT deficiency, no significant differences in CRP, sCD14, TNF- $\alpha$, sTNFR-1, and STNFR-2 levels comparing all genotypic groups studied were seen.

In COPD patients without AAT deficiency ( $\mathrm{PI}^{\star} \mathrm{MM}$ genotypic group), a significant negative correlation between lung function, and serum AAT and CRP concentrations was seen as well as a positive correlation between AAT and CRP, sCD14, and STNFR-1 (Table III).

However, no correlation was documented in COPD patients with AAT deficiency $\left(\mathrm{PI}^{\star} \mathrm{MM}, \mathrm{PI}^{\star} \mathrm{MZ}\right.$, and $\mathrm{PI}{ }^{*} \mathrm{SZ}$ genotypic groups).

\section{Discussion}

An important finding of our study is that circulating AAT inversely correlated with $\mathrm{FEV}_{1}$ in COPD patients without AAT deficiency. Such associations have also been reported before in healthy individuals [18-21]. The SAPALDIA study investigated circulating AAT associations with lung function in the general population and found a negative correlation between $A A T$ level and $\mathrm{FEV}_{1}$ [19]. The quantity of AAT that diffuses passively from the blood to the lung increases during an inflammatory process, which may take place in COPD [22]. This may indicate increased requirement of AAT to meet the needs of overcoming the release of various enzymes from neutrophilic cells in the lungs, but its protective function may be overrun by the high concentration of proteases [23]. However, other
Table I. General data of study population

\begin{tabular}{|lc|}
\hline Variable & Values \\
\hline Age [years] & $63.4 \pm 11.9$ \\
\hline Males/females, $n(\%)$ & $252(71) / 103(29)$ \\
\hline \begin{tabular}{l} 
Smoking status: \\
\cline { 2 - 2 } Smokers, $n(\%)$
\end{tabular} \\
\hline Ex-smokers, $n(\%)$ & $210(59.2)$ \\
\hline Never smokers, $n(\%)$ & $76(21.4)$ \\
\hline FVC (mean \pm SD) [\% predicted normal] & $74.1 \pm 16.2$ \\
\hline FEV ${ }_{1}$ (mean \pm SD) [\% predicted normal] & $47.4 \pm 16.6$ \\
\hline FEV 1 /FVC (mean \pm SD) [\%] & $54.7 \pm 11.1$ \\
\hline
\end{tabular}

Data are presented as mean $\pm S D$, unless otherwise indicated. $F V C$ - forced vital capacity, FEV 1 -forced expiratory volume in $1 \mathrm{~s}$

studies have not found such associations between serum AAT concentration and $\mathrm{FEV}_{1} \%$ predicted value in COPD patients [24]. It appears that many other mechanisms may also be important for lung function and not just for the inflammatory response.

The observed low AAT concentration in $\mathrm{PI}^{\star} \mathrm{ZZ}$ genotype and the $\mathrm{FEV}_{1}$ /AAT association may reflect the dual role of AAT as a biomarker of respiratory disease. The net impact of AAT on lung function seems to be the result of context-dependent (i.e. AAT genotype) and contrasting protective and inflammatory effects in the respiratory tract. On the one hand, elevated levels of serum AAT can reflect a beneficial shift in the protease-antiprotease balance, the cornerstone of the pathophysiological pathway mediating the effect of severe AAT deficiency on COPD. On the other hand, elevated serum AAT can also reflect low-grade inflammatory processes in the lungs [25], which are considered a risk factor for COPD [26]. Significantly higher AAT levels were even reported for AAT deficient (PI*ZZ) patients with COPD as compared to $\mathrm{PI}{ }^{\star} \mathrm{ZZ}$ individuals without COPD, further supporting the hypothesis that AAT levels may also represent an ongoing inflammatory process [27]. Thus, the findings of our

Table II. Serum concentrations of AAT, sCD14, CRP, TNF- $\alpha$, TNFR-1, and TNFR-2 in COPD patients with different AAT genotypes

\begin{tabular}{|c|c|c|c|c|c|}
\hline \multirow[t]{2}{*}{ Variable } & \multicolumn{4}{|c|}{ Genotype } & \multirow{2}{*}{$\begin{array}{l}\text { Value of } p \\
\text { among groups }\end{array}$} \\
\hline & $\mathrm{PI}{ }^{*} \mathrm{MM}(n=320)$ & $\mathrm{PI}{ }^{\star} \mathrm{MZ}(n=25)$ & $\mathrm{PI}{ }^{*} \mathrm{ZZ}(n=7)$ & $\mathrm{PI}{ }^{\star} \mathrm{SZ}(n=3)$ & \\
\hline AAT $[\mathrm{g} / \mathrm{l}]$ & $1.65 \pm 0.48$ & $1.10 \pm 0.30$ & $0.46 \pm 0.40$ & $0.77 \pm 0.19$ & 0.001 \\
\hline $\mathrm{sCD} 14[\mu \mathrm{g} / \mathrm{ml}]$ & $2.9 \pm 1.3$ & $3.1 \pm 1.5$ & $2.9 \pm 0.4$ & $3.9 \pm 0.2$ & NS \\
\hline CRP $[\mathrm{mg} / \mathrm{l}]$ & $9.6 \pm 3.2$ & $10.2 \pm 5.4$ & $8.3 \pm 2.9$ & $7.2 \pm 1.5$ & NS \\
\hline TNF- $\alpha[\mathrm{pg} / \mathrm{ml}]$ & $113.7 \pm 25.2$ & $56.1 \pm 11.6$ & $75.4 \pm 22.5$ & 0 & NS \\
\hline sTNFR-1 [pg/ml] & $221.9 \pm 77.1$ & $204.4 \pm 62.3$ & $168.1 \pm 49.3$ & $347.4 \pm 109$ & NS \\
\hline sTNFR-2 [pg/ml] & $231.4 \pm 88.9$ & $219.1 \pm 76.0$ & $219.2 \pm 69.6$ & $223.1 \pm 77.5$ & NS \\
\hline
\end{tabular}

All data are presented as mean $\pm S D$. AAT - $\alpha 1$ antitrypsin, $S C D$ - soluble leukocyte cluster of differentiation, CRP - C-reactive protein, TNF- $\alpha$-tumor necrosis factor $\alpha$, TNFR - tumor necrosis factor $\alpha$ receptor, NS - not significant 
Table III. Correlation between inflammatory marker concentrations and lung function ( $\mathrm{FEV}_{1}, \%$ predicted) in COPD patients without AAT deficiency

\begin{tabular}{|lcc|}
\hline Variables & $r$ & Value of $p$ \\
\hline AAT vs. CRP & 0.671 & 0.005 \\
\hline AAT vs. SCD14 & 0.510 & 0.008 \\
\hline AAT vs. sTNFR-1 & 0.567 & 0.007 \\
\hline AAT vs. FEV 1 & -0.522 & 0.03 \\
\hline CRP vs. STNFR-1 & 0.507 & 0.006 \\
\hline CRP vs. FEV 1 & -0.590 & 0.011 \\
\hline sTNFR-1 vs. sTNFR-2 & 0.643 & 0.009 \\
\hline
\end{tabular}

$A A T-\alpha 1$ antitrypsin, $S C D$ - soluble leukocyte cluster of differentiation, $C R P-C$-reactive protein, TNF- $\alpha$ - tumor necrosis factor $\alpha$, TNFR - tumor necrosis factor a receptor, $F E V_{1}$ - forced expiratory volume in $1 \mathrm{~s}$, $r$-Spearman correlation coefficient

study suggest that pulmonary obstruction may be a consequence of the presence of inflammatory stimuli.

Consistent with these results, we could detect a positive relationship between AAT and CRP concentrations. High serum CRP concentrations in severe COPD patients have been reported in previous studies [18, 24, 28]. Gan et al. were the first to emphasize the importance of high CRP levels in COPD patients, confirming the systemic inflammation in the stable phase of the disease [26]. Studies of circulating CRP levels in COPD demonstrated that CRP was further elevated during exacerbations, and it was found to predict mortality [29]. Both AAT and CRP are acute-phase proteins. Several studies have found elevated CRP and AAT levels in COPD patients [7, 24], indicating that the inflammatory process is present in disease pathogenesis, and both markers are interrelated.

In addition, we found an inverse correlation

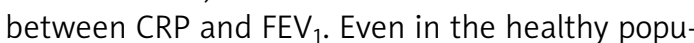
lation, increases in CRP levels over time were associated with a steeper $\mathrm{FEV}_{1}$ decline [30, 31]. In these studies, $\mathrm{FEV}_{1}$ was also inversely associated with CRP concentration. C-reactive protein reflects the total systemic burden of inflammation in several disorders and has been shown to upregulate the production of proinflammatory cytokines [7]. The reasons for the inverse association between systemic inflammation and reduced pulmonary function are not fully understood, but several mechanisms may be involved. Firstly, reduced lung function may be responsible for the observed systemic inflammation. Inflammatory lung or pulmonary epithelial cells have been shown to express CRP and IL-6 [32]. Interleukin-6 may reach the liver via the bloodstream, stimulating the production of CRP and other inflammatory mediators by the liver, sequentially activating pulmonary inflammatory cells during transit through the pulmonary circulation $[33,34]$. An alternative mechanism - reverse causation - cannot be excluded: high levels of cytokines and acute-phase reactants in the peripheral circulation may be a cause rather than a consequence of poor lung function. There is increasing evidence that cytokines play a major role linked to the activation of inflammatory cells and their adhesion to the pulmonary capillary endothelium, leading to changes in endothelial function and increases in pulmonary vascular filtration [18]. Besides, it is known that COPD may even influence venous circulation [35]. Thus, persistence of systemic inflammation may result in damage to the airways, accelerating decline in $\mathrm{FEV}_{1}$ of COPD patients.

In our study, an important marker, TNF- $\alpha$, has been analyzed. This inflammatory cytokine is important in COPD pathogenesis [3] and processes where AAT is involved $[36,37]$. In vitro studies have demonstrated that AAT inhibits TNF- $\alpha$ production [36]. However, no associations between serum TNF- $\alpha$ concentration and other parameters have been found in our study. It is observed that TNF- $\alpha$ levels may be elevated in the sputum, bronchial biopsies, and circulation of COPD patients $[3,26]$. Other investigators analyzing TNF- $\alpha$ level in COPD patients did not find any association with the severity of disease [7]. One possible explanation for this could be that these cytokines mainly act in peripheral lung tissues and differences in their levels could be detected in induced sputum but not always in systemic circulation [38]. Thus, in our study, STNFR-1 was positively correlated with inflammatory markers - AAT and CRP. In addition, a positive correlation between STNFR-1 and STNFR-2 was documented. These soluble receptors, which inhibit the inflammatory effect of TNF- $\alpha$, are expressed and released from many different cells, enabling even elevation of concentration in systemic circulation, where they can be detected [8]. Our results show that elevated STNFR-1 levels may reflect a systemic inflammatory response.

Recent studies show similar cellular responses in asthma and COPD, with raised levels of neutrophils [39, 40]. Monocytes/macrophages are a significant component of inflammatory infiltrate in COPD [41, 42]. Analyzing SCD14 levels in COPD patients, we did not find any differences in SCD14 levels among different AAT genotypes. Thus, we found a positive correlation between SCD14 and AAT. CD14-dependent mechanisms of inflammation have also been discussed in acute respiratory distress syndrome [43]. The soluble form of CD14 is generated by proteolytic shedding of the membrane-associated form during cellular activation [44]. In vitro within $2 \mathrm{~h}$ (short time), AAT strongly up-regulates sCD14 secretion and membrane CD14 (mCD14) expression, while after $18 \mathrm{~h}$, it causes a profound decrease in $\mathrm{mCD} 14$ expression [16]. This observation provides evidence that a direct rela- 
tionship exists between the accumulation of sCD14 and the reciprocal decrease in $\mathrm{mCD} 14$ expression. The biological function of SCD14 is not clear so far. An excess of sCD14 is shown to inhibit LPS binding to mCD14 and hence block cellular activation [16]. Recent findings support the hypothesis that modulation of LPS-induced monocyte activation by AAT may be related to the AAT-induced modulation of CD14 levels [36].

These data show that AAT has immunomodulating capacity, and a rapid increase in AAT concentrations during various inflammatory and infectious conditions may enhance the magnitude of inflammatory cell responses to endotoxin and subsequently accelerate resolution of the inflammatory reaction [42, 45]. However, the associations are complex and understanding the interplay of various mediators will require appropriately designed further studies.

In conclusion, the present study indicated that for expected lower AAT serum concentrations in COPD patients with $\mathrm{PI}^{\star} \mathrm{ZZ}$ genotype, there were no significant differences in CRP, sCD14, TNF- $\alpha$, STNFR-1, and STNFR-2 levels comparing patients with different AAT genotypes. In patients without AAT deficiency, the positive association of AAT concentration with CRP, SCD14, and STNFR-1 and the negative association with FEV1 show the importance of AAT as a marker of systemic inflammation.

\section{Acknowledgments}

This study was supported in part by the Scientific Foundation of the Lithuanian University of Health Sciences (Project Grant PAR8) and the Swedish Medical Research Council.

\section{References}

1. Global Initiative for Chronic Obstructive Lung Disease (GOLD 2006). Global strategy for the diagnosis, management, and prevention of COPD, Executive Summary. Date last accessed: August 2008.

2. Wouters EF. Chronic obstructive pulmonary disease. 5: systemic effects of COPD. Thorax 2002; 57: 1067-70.

3. Chung KF. Cytokines as targets in chronic obstructive pulmonary disease. Curr Drug Targets 2006; 7: 675-81.

4. Gan WQ, Man SFP, Senthilselvan A, Sin DD. Association between chronic obstructive pulmonary disease and systemic inflammation: a systematic review and a metaanalysis. Thorax 2004; 59: 574-80.

5. Pinto-Plata VM, Müllerova H, Toso JF, et al. C-reactive protein in patients with COPD, control smokers, and nonsmokers. Thorax 2006; 61: 23-8.

6. Pinto-Plata VM, Livnat G, Girish M, et al. Systemic cytokines, clinical and physiological changes in patients hospitalized for exacerbation of COPD. Chest 2007; 13: 37-43.

7. Karadag F, Kirdar S, Karul AB, Ceylan E. The value of $C$-reactive protein as a marker of systemic inflammation in stable chronic obstructive pulmonary disease. Eur J Intern Med 2008; 19: 104-8.
8. Bradley JR. TNF-mediated inflammatory disease. J Pathol 2008; 214: 149-60.

9. American Thoracic Society/European Respiratory Society Statement: standards for the diagnosis and management of individuals with alpha1-antitrypsin deficiency. Am J Respir Crit Care Med 2003; 168: 818-900.

10. Janoff A, Sloan B, Weinbaum G, et al. Experimental emphysema induced with purified human neutrophil elastase: tissue localization of the instilled protease. Am Rev Respir Dis 1977; 115: 461-78.

11. Hadzic R, Nita I, Tassidis H, Riesbeck K, Wingren AG, Janciauskiene S. Alpha-1 antitrypsin inhibits Moraxella catarrhalis MID protein-induced tonsillar B cell proliferation and IL-6 release. Immunol Lett 2006; 102: 141-7.

12. Watt AP, Schock BC, Ennis M. Neutrophils and eosinophils: clinical implications of their appearance, presence and disappearance in asthma and COPD. Curr Drug Targets Inflamm Allergy 2005; 4: 415-23.

13. van der Vaart $\mathrm{H}$, Postma DS, Timens W, et al. Acute effects of cigarette smoking on inflammation in healthy intermittent smokers. Respir Res 2005; 6: 22.

14. Mulgrew A, Taggart CC, Lawless MW, et al. Alpha-1 Antitrypsin polymerizes in the lung and acts as a neutrophil chemoattractant. Chest 2004; 125: 1952-7.

15. Janciauskiene SM, Stevens T, Blanco I. New insights into the biology of $\alpha 1$-antitrypsin and its role in chronic obstructive pulmonary disease. Curr Respir Med Rev 2007; 3: $147-58$.

16. Nita IM, Serapinas D, Janciauskiene SM. Alpha1-Antitrypsin regulates CD14 expression and soluble CD14 levels in human monocytes in vitro. Int J Biochem Cell Biol 2007; 39: 1165-76.

17. Pierce JA, Eradio BG. Improved identification of antitrypsin phenotypes through isoelectric focusing with dithioerythritol. J Lab Clin Med 1979; 94: 826-31.

18. Garcia-Rio F, Miravitlles M, Soriano JB, et al. Systemic inflammation in chronic obstructive pulmonary disease: a population-based study. Respir Res 2010; 11: 63.

19. Senn O, Russi EW, Schindler C, et al. Circulating alpha1antitrypsin in the general population: determinants and association with lung function. Respir Res 2008; 9: 35.

20. Engström G, Lind P, Hedblad B, et al. Lung function and cardiovascular risk: relationship with inflammationsensitive plasma proteins. Circulation 2002; 106: 2555-60.

21. Welle I, Bakke PS, Eide GE, Fagerhol MK, Omenaas E, Gulsvik A. Increased circulating levels of alpha1-antitrypsin and calprotectin are associated with reduced gas diffusion in the lungs. Eur Respir J 2001; 17: 1105-11.

22. Stockley RA, Burnett D. Alpha1-antitrypsin and leukocyte elastase in infected and non-infected sputum. Am Rev Respir Dis 1979; 120: 1081-6.

23. Owen CA, Campbell EJ. Extra-cellular proteolysis: new paradigms for an old paradox. J Lab Clin Med 1999; 134: 341-51.

24. Higashimoto Y, Yamagata Y, Taya S, Iwata T, Okada M, Ishiguchi T. Systemic inflammation in chronic obstructive pulmonary disease and asthma: similarities and differences. Respirology 2008; 13: 128-33.

25. Meyer KC, Rosenthal NS, Soergel P, Peterson K. Neutrophils and low-grade inflammation in the seemingly normal aging human lung. Mech Ageing Dev 1998; 104: 169-81.

26. Gan WQ, Man SF, Senthilselvan A, Sin DD. Association between chronic obstructive pulmonary disease and systemic inflammation: a systematic review and a metaanalysis. Thorax 2004; 59: 574-80.

27. Silverman EK, Province MA, Rao DC, Pierce JA, Campbell EJ. A family study of the variability of pulmonary function 
in alpha 1-antitrypsin deficiency. Quantitative phenotypes. Am Rev Respir Dis 1990; 142: 1015-21.

28. Barnes PJ, Shapiro SD, Pauwels RA. Chronic obstructive pulmonary disease: molecular and cellular mechanisms. Eur Respir J 2003; 22: 672-88.

29. Sin DD, Man SF. Why are patients with chronic obstructive pulmonary disease at increased risk of cardiovascular diseases? The potential role of systemic inflammation in chronic obstructive pulmonary disease. Circulation 2003; 107: 1514-9.

30. Shaaban R, Kony S, Driss F, et al. Change in C-reactive protein levels and FEV1 decline: a longitudinal populationbased study. Respir Med 2006; 100: 2112-20.

31. Kony S, Zureik M, Driss F, Neukirch C, Leynaert B, Neukirch F. Association of bronchial hyperresponsiveness and lung function with C-reactive protein (CRP): a population based study. Thorax 2004; 59: 892-6.

32. Gould JM, Weiser JN. Expression of C-reactive protein in the human respiratory tract. Infect Immun 2001; 69: 1747-54.

33. Van Eeden SF, Tan WC, Suwa T, et al. Cytokines involved in the systemic inflammatory response induced by exposure to particulate matter air pollutants (PM10). Am J Respir Crit Care Med 2001; 164: 826-30.

34. Sin DD, Lacy P, York E, Man SF. Effects of fluticasone on systemic markers of inflammation in chronic obstructive pulmonary disease. Am J Respir Crit Care Med 2004; 170: 760-5.

35. Lessiani G, Falco A, Franzone G, Saggini R, Davi G. Prevalence of deep vein thrombosis in patients affected by exacerbation of mild to moderate COPD at stage I-II of GOLD classification. Arch Med Sci 2008; 4: 62-5.

36. Janciauskiene SM, Nita IM, Stevens T. Alpha1-antitrypsin, old dog, new tricks. Alpha1-antitrypsin exerts in vitro antiinflammatory activity in human monocytes by elevating CAMP. J Biol Chem 2007; 282: 8573-82.

37. Libert C, Van Molle W, Brouckaert P, Fiers W. Alpha1Antitrypsin inhibits the lethal response to TNF in mice. J Immunol 1996; 157: 5126-9.

38. Hacievliyagil SS, Gunen H, Mutlu LC, Karabulut AB, Temel I. Association between cytokines in induced sputum and severity of chronic obstructive pulmonary disease. Respir Med 2006; 100: 846-54

39. Hollander C, Sitkauskiene B, Westin U, Sakalauskas R, Janciauskiene SM. Serum and bronchial lavage fluid concentrations of IL-8, SLPI, SCD14 and SICAM- 1 in patients with COPD and asthma. Respir Med 2007; 101: 1947-53.

40. Katakanon A, Uasuf C, Maziak W, Lim S, Chung KF, Barnes PJ. Neutrophilic inflammation in severe persistent asthma. Am J Respir Crit Care Med 1999; 160: 1532-9.

41. Rutgers SR, Postam DS, ten Hacken NH, et al. Ongoing airway inflammation in patients with COPD who do not currently smoke. Thorax 2000; 55: 12-8.

42. Pinto-Plata V, Toso J, Lee K, et al. Profiling serum biomarkers in patients with COPD: associations with clinical parameters. Thorax 2007; 62: 595-601.

43. Martin TR, Rubenfeld GD, Ruzinski JT, et al. Relationship between soluble CD14, lipopolysaccharide binding protein, and the alveolar inflammatory distress sindrome. Am J Respir Crit Care Med 1997; 155: 937-44.

44. Sandström CS, Novoradovskaya N, Cilio CM, Piitulainen E, Sveger T, Janciauskiene S. Endotoxin receptor CD14 in PiZ alpha-1-antitrypsin deficiency individuals. Respir Res 2008; 9: 34.

45. Molfino NA. Current thinking on genetics of chronic obstructive pulmonary disease. Curr Opin Pulm Med 2007; 13: 107-13. 